\title{
DESAIN BAHAN AJAR BERBASIS KEMAMPUAN BERPIKIR KRITIS DENGAN MODEL COMPREHENSIVE MATHEMATICS INSTRUCTION
}

\author{
Indri Sri Haryanti $^{\text {1), Ika Wahyuni }}{ }^{2)}$, Dina Pratiwi Dwi santi ${ }^{3)}$ \\ ${ }^{122) 3)}$ Program Studi Pendidikan Matematika FKIP Unswagati, Cirebon, Indonesia; \\ haryantiindrisri@gmail.com, ik.math84@gmail.com,dinapratiwids@fkip-unswagati.ac.id
}

\begin{abstract}
This research is motivated by the low critical thinking skills of students and learning activities that do not stimulate the emergence of students' skills in mathematics. Researcher found the obstacle learning experienced by students when solving problems in the matriks material. So that researchers create innovations by making matrix teaching materials based on critical thinking skills in anticipation of didactic as well as using CMI models which are packaged into learning activities as pedagogical anticipation The purpose of this study is to determine the validity and practicality of teaching materials. This research belongs to the type of development research. Module was developed using a qualitative approach. The development method carried out is the DDR stage. The data collection technique was by test and non-test. The instruments used are test questions and questionnaires. The subjects in this study were 25 students of class XI MIPA 3 of SMAN 1 Lohbener. The results of the study are: based on cumulative validation calculations, teaching materials obtain a validity percentage of $90.68 \%$ with validity interpretations which are very valid. Then based on cumulative practicality calculations, teaching materials get a practical percentage of $73 \%$ with practicality interpretations namely practical.
\end{abstract}

Keywords: Teaching materials, Critical thinking, Comprehensive Mathematics Instruction, Didactical Design Research.

Abstrak
Penelitian ini dilatar belakangi karena rendahnya kemampuan berpikir kritis
siswa dan aktivitas pembelajaran yang kurang memacu munculnya keterampilan
siswa dalam bermatematika. Peneliti menemukan learning obstacle yang dialami
siswa saat menyelesaikan permasalahan pada materi matriks. Sehingga peneliti
menciptakan inovasi dengan membuat bahan ajar matriks berbasis kemampuan
berpikir kritis sebagai antisipasi didaktis juga menggunakan model Comprehensive
Mathematics Instruction (CMI) yang dikemas menjadi aktivitas belajar sebagai
antisipasi pedagogis Tujuan dari penelitian ini adalah untuk mengetahui kevalidan
dan kepraktisan bahan ajar. Penelitian ini termasuk ke dalam jenis penelitian
pengembangan. Desain bahan ajar dikembangkan dengan menggunakan pendekatan
kualitatif. Metode pengembangan yang dilakukan adalah tahapan Didactical Design
Research (DDR). Teknik pengumpulan data dalam penelitian ini adalah dengan tes
dan non tes. Instrumen yang digunakan adlah soal tes dan angket. Subjek pada


penelitian ini adalah 25 siswa kelas XI MIPA 3 SMAN 1 Lohbener. Hasil penelitian adalah: berdasarkan perhitungan validasi secara kumulatif, bahan ajar memperoleh persentase kevalidan sebesar 90,68\% dengan interpretasi kevalidan yaitu sangat valid. Kemudian berdasarkan perhitungan uji praktikalitas secara kumulatif, bahan ajar mendapatkan persentase kepraktisan sebesar $73 \%$ dengan interpretasi kepraktisan yaitu praktis.

Kata kunci: Bahan ajar, berpikir kritis, Comprehensive Mathematics Instruction, Didactical Design Research.

\section{PENDAHULUAN}

Menurut NCTM 2000 (Delima \& Fitriza, 2017) terdapat lima standar proses dalam pembelajaran matematika yakni problem solving, reasoning and proof, connections, dan representation. Artinya kemampuan- kemampuan matematis perlu diperhatikan dalam kegiatan pembelajaran matematika. Selain itu perkembangan matematika dapat diukur dari kemampuan matematisnya yang berkembang misalnya dengan adanya kemampuan berpikir tingkat tinggi diantaranya kemampuan berpikir kritis matematis siswa. Kemampuan berpikir kritis sangatlah penting untuk dimiliki oleh siswa, seperti yang dikemukakan oleh Wahyuni dan Efuansyah (2018) bahwa kemampuan berpikir kritis matematis sangat diperlukan agar siswa dapat memecahkan masalah matematika. Dengan kata lain, tidak berkembangnya kemampuan berpikir kritis akan menghambat kemampuan siswa dalam menyelesaikan masalah matematika. Sehingga dapat diketahui bahwa kemampuan berpikir kritis dapat menjadi awal terbentuknya kemampuan matematis lainnya seperti kemampuan berpikir kreatif dan kemampuan pemecahan masalah.

Berdasarkan observasi yang sudah dilakukan di salah satu SMKN di kabupaten Cirebon ditemukan bahwa, dalam pembelajaran matematika pengembangan kemampuan berpikir kritis matematis belum sepenuhnya dapat diterapkan. Umumnya siswa cenderung mengalami kesulitan menganalisis masalah matematika dalam bentuk soal cerita dan soal yang dikembangkan. Soal yang dimaksud adalah yang dikaitkan dengan materi lainnya. Berikut merupakan contoh learning obstacles untuk kemampuan berpikir kritis dengan materi matriks:

Contoh soal matriks:

Diketahui matriks $P=$ $\left(\begin{array}{ccc}2 & -3 & 6 \\ 5 & 0 & -2 \\ 1 & 4 & -4\end{array}\right)$, nilai $\left(A_{12}-A_{31}\right)$ dari transpose matriks $\mathrm{P}$ adalah .

Kemudian di bawah ini adalah jawaban dari soal yang disajikan di atas. 


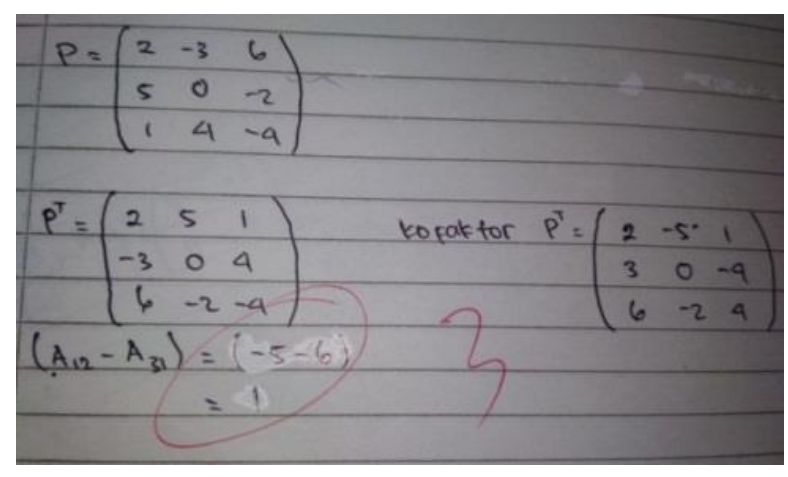

Gambar 1. Contoh learning obstacle siswa

Ditemukan sebagian besar jawaban siswa, tidak mencari matriks kofaktor melainkan mentransposekan matriks $P$. Jelas ini merupakan kesalahan karena siswa mengerjakan soal tidak sesuai dengan apa yang diperintahkan dalam soal. Masalah tersebut tidak semata- mata sepenuhnya kekeliruan dari peserta didik. Hal itu dapat terjadi karena cara pembelajaran matematika yang belum sempurna sehingga perlu diperbaiki guna meningkatkan kemampuan berpikir kritis siswa menjadi lebih baik. Menerapkan model Comprehensive Mathematics Instruction (CMI) merupakan inovasi baru sebagai bentuk antisipasi pedagogis bagi siswa. selain model pembelajaran yang merupakan antisipasi pedagogis, desain bahan ajar yang digunakan juga haruslah dijabarkan secra jelas dan sistematis dalam penyajian materi, contoh soal merupakan soal yang dibuat berdasarkan indikator dari kemampuan berpikir kritis. Selain itu desain bahan ajar dikemas menggunakan tahapan dari model CMI yang berbasis pembelajaran kelompok sehingga siswa dapat memperbaiki kemampuannya dalam menyelesaikan masalah matematika pada materi matriks.
Berdasarkan penjelasan di atas, guna menanggulangi masalah pada pembelajaran matematika maka disusunlah desain bahan ajar. Sehingga judul pada penelitian ini adalah "Desain Bahan Ajar Berbasis Kemampuan Berpikir Kritis Siswa dengan Model Comprehensive Mathematics Instruction (CMI). Adapun rumusan masalah yang diangkat dalam penelitian ini adalah bagaimana desain bahan ajar berbasis kemampuan berpikir kritis dengan model CMI yang valid dan praktis. Dengan tujuan untuk mendeskripsikan bahan ajar materi matriks yang valid dan praktis.

\section{LANDASAN TEORI}

\section{Didactical Desain Research}

Menurut Plomp (Mardiana: 2013) "Design research adalah suatu kajian sistematis tentang merancang, mengembangkan dan mengevaluasi intervensi pendidikan (seperti program, strategi dan bahan pembelajaran, produk dan sistem) sebagai solusi untuk memecahkan masalah yang kompleks dalam praktik pendidikan, yang juga bertujuan untuk memajukan pengetahuan kita tentang karakteristik 
dan intervensi-intervensi tersebut serta proses perancangan dan pengembangannya". Dengan demikian DDR adalah penelitian yang mengupayakan perkembangan matematika di masa depan dengan mengembangkan, merancang dan mengevaluasi intervensi pendidikan sebagai solusi untuk memecahkan masalah kompleks dalam pendidikan, serta untuk mengembangkan kualitas pendidik dan siswa. Menurut Suryadi (2011: 12) penelitian desain didaktis pada dasarnya terdiri atas tiga tahap, yaitu: (1) analisis situasi didaktis sebelum pembelajaran yang wujudnya berupa Desain Didaktis Hipotesis termasuk ADP; (2) analisis metapedadidaktik; dan (3) analisis retrosfektif yakni analisis yang mengaitkan hasil analisis situasi didaktis hipotesis dengan hasil analisis metapedadidaktik.

\section{Modul}

Kodir (2010: 219) mengemukakan bahwa modul adalah alat atau sarana pembelajaran yang berisi materi, metode, batasan-batasan materi pembelajaran, petunjuk kegiatan belajar, latihan, dan cara mengevaluasi yang dirancang secara sistematis dan menarik untuk mencapai kompetensi yang diharapkan dan dapat digunakan sendiri. Modul diartikan sebagai buku yang ditulis secara sistematis dan menarik dengan tujuan agar siswa dapat belajar secara mandiri tanpa atau dengan bimbingan guru. Diknas (Prastowo, 2015: 104) menyebutkan bahwa modul juga dapat digunakan sebagai saran pembelajaran yang memunculkan kemampuan matematis siswa melalui desain yang dibuat baik itu dari penyampaian materi, soal latihan dan lain-lain. Struktur modul menurut Surahman (Prastowo, 2011: 113) dapat disusun sebagai berikut: (a) judul buku; (b) petunjuk umum; (c) materi modul; dan (d) evaluasi semester. Dalam menyusun modul, ada empat tahapan yang harus dilalui, yaitu analisis kurikulum, penentuan juduljudul modul, pemberian kode modul, dan penulisan modul.

Menurut Surahman (Prastowo, 2015: 113) mengemukakan bahwa modul dapat disusun dalam struktur sebagai berikut:

a. Judul modul (bagian ini berisi tentang nama modul dari materi tertentu).

b. Petunjuk umum (bagian ini berisi tentang kompetensi dasar, pokok bahasan, indikator pencapaian, referensi, strategi pembelajaran, lembar kegiatan pembelajaran, petunjuk bagi siswa untuk memahami langkah-langkah dan materi, evaluasi).

c. Materi modul (bagian ini berisi tentang penjalasan secara rinci tentang materi yang akan disampaikan pada setiap pertemuan).

d. Evaluasi semester (evaluasi ini terdiri atas evaluasi tengah semester dan akhir semester dengan tujuan untuk mengukur kompetensi mahasiswa sesuai materi kuliah yang diberikan).

Berdasarkan penjelasan struktur di atas, dalam penelitian ini penulis 
menggunakan kerangka bahan ajar modul sebagai berikut: (a) Halaman sampul, (b) sampul dalam, (c) kata pengantar, (d) daftar isi, (e) peta konsep, (f) materi modul, (g) daftar pustaka, dan (h) glosarium.

\section{Kemampuan Berpikir Kritis Matematis}

\section{Langrehr (Miliyawati:} 2017) mengemukakan bahwa chritical thinking merupakan berpikir evaluatif yang melibatkan kriteria yang relevan dalam mengakses informasi disertai dengan ketepatan, relevansi, kepercayaan, ketegapan (consistency), dan mengidentifikasi bias. Penelitian ini mengukur kemampuan berpikir kritis matematis dengan indikator seperti yang disebutkan oleh Ennis (1980) yaitu: memberikan penjelasan sederhana, membangun keterampilan dasar, menyimpulkan, memeberikan penjelasan lebih lanjut, mengatur strategi dan teknik. Untuk mengetahui lebih lengkapnya mengenai penjelasan kelima indikator kemampuan berpikir kritis tersebut selengkapnya dapat dilihat dalam Tabel 1.

Tabel 1. Proses dan Kata-Kata Operasional Berpikir Kritis

\begin{tabular}{|c|c|c|}
\hline No. & Indikator & Kata-Kata Operasional \\
\hline 1 & $\begin{array}{l}\text { Memberikan penjelasan } \\
\text { sederhana }\end{array}$ & $\begin{array}{l}\text { Menganalisis } \\
\text { mengajukan dan } \\
\text { pertanyaan klarifikasi }\end{array}$ \\
\hline 2 & $\begin{array}{l}\text { Membangun keterampilan } \\
\text { dasar }\end{array}$ & $\begin{array}{l}\text { Menilai kredibilitas suatu sumber, } \\
\text { meneliti, menilai hasil penelitian }\end{array}$ \\
\hline 3 & Membuat inferensi & $\begin{array}{l}\text { Mereduksi dan menilai deduksi, } \\
\text { menginduksi dan menilai induksi, } \\
\text { membuat dan menilai penilaian yang } \\
\text { berharga }\end{array}$ \\
\hline 4 & $\begin{array}{l}\text { Membuat penjelasan lebih } \\
\text { lanjut }\end{array}$ & $\begin{array}{l}\text { Mendefinisikan istilah, menilai } \\
\text { definisi, mengidentifikasi asumsi }\end{array}$ \\
\hline 5 & $\begin{array}{lll}\begin{array}{l}\text { Mengatur strategi dan } \\
\text { teknik }\end{array} & \end{array}$ & $\begin{array}{l}\text { Memutuskan sebuah tindakan, } \\
\text { berinteraksi dengan orang lain }\end{array}$ \\
\hline
\end{tabular}

soal yang dapat mengukur indikator kemampuan berpikir kritis

Soal :

Jika diketahui $\operatorname{det}(A)=0$ dari matriks $A=\left(\begin{array}{cc}-5 & p+4 \\ P-2 & 1\end{array}\right)$

Maka tentukanlah:

a. Semua nilai $p$ dari matriks $A$

b. Jelaskan apakah matriks $A$ memiliki invers atau tidak

\section{Comprehensive Instruction (CMI)}

Mathematics

Hendrickson, Hilton, \& Bahr (2008) mengemukakan bahwa "The CMI framework is intended to be a structured set of basic principles and productive practices, that can lead students to deeper mathematical understanding" yang berarti kerangka CMI dimaksudkan sebagai seperangkat prinsip dasar dan praktik produktif yang 
dapat mengarahkan siswa untuk memahami secara mendalam dengan meminimalisir ketidakseimbangan antara dua kecakapan tersebut yaitu instruksi tradisional dan instruksi reformasi.

Kerangka CMI menurut Hendrickson, Hilton, \& Bahr (Delima \& Fitrizia, 2017) terdiri dari tiga komponen utama, yakni: (1) Teaching cycle, Delima \& Fitrizia (2017) mengungkapkan bahwa komponen teaching cycle dalam pembelajaran matematika merupakan suatu siklus dalam pembelajaran tradisional seperti mereview pekerjaan rumah (Launch), memperkenalkan materi, memberi pembelajaran, memberikan soal-soal latihan (Explore), dan kemudian siswa belajar mandiri untuk menyelesaikan masalah (Discuss); (2) Learning cycle, Delima \& Fitrizia (2017) pembelajaran matematika yang berlangsung di kelas sebaiknya, mengikuti tahapan dalam komponen Learning Cycle, tahapan yang dimaksud yakni, pertama adalah tahapan mengenai bagaimana mengarahkan cara berpikir siswa agar sesuai dengan tujuan dari materi matematika yang dipilih (Develop Understanding), kemudian meluas dan menguat pada bagaimana mengarahkan siswa agar berpikir dengan benar dan relevan tentang materi tersebut (Solidify Understanding), dan pada akhirnya mengarahkan siswa agar mulai menyaring hasil pemikiran mereka dalam rangka memperoleh kesesuaian pemikiran dengan teman-temannya melalui diskusi (Practice Understanding); (3) Continum of Mathematical Understanding, Delima
\& Fitrizia (2017) mengemukakan bahwa Proses pembentukan pemahaman matematik akan berlangsung secara terus menerus pada sepanjang garis kontinum dalam learning cycle (develope, solidify, practice.

CMI merupakan inovasi baru dalam pembelajaran matematika yang memiliki potensi tepat guna dalam mengembangkan pembelajaran matematika. Hendrickson, Hilton, \& Bahr (2008) menegaskan bahwa kerangka kerja CMI dapat digunakan oleh guru kelas sebagai alat pedagogis sebelum, selama dan setelah mengajar. Sebelum mengajar, kerangka tersebut memberikan perencanaan merancang pembelajaran untuk memenuhi tujuan yang diinginkan dan hasil belajar yang diinginkan. Guru diharapkan dapat mengantisipasi pemikiran siswa dan untuk mangarahkan bagaimana mereka akan melakukan diskusi dari pemikiran ini untuk mengembangkan dan memperkuat pemahaman yang benar. Hal itu terus dilakukan hingga siswa diijinkan untuk mengeksplorasi pemikiran matematika sehingga guru tidak mengambil peran sebagai otoritas matematis tunggal di kelas.

\section{METODE PENELITIAN}

\section{Jenis Penelitian}

Penelitian ini menggunakan jenis penelitian pengembangan. Desain bahan ajar dikembangkan dengan menggunakan pendekatan kualitatif. Metode pengembangan yang dilakukan adalah tahapan Didactical Design Research (DDR). 


\section{Subjek Penelitian}

Subjek pada penelitian ini adalah 25 siswa kelas XI MIPA 3 SMAN 1 Lohbener

\section{Prosedur}

Secara garis besar, penelitian yang dilakukan melalui tahapan penelitian desain didaktis pada dasarnya terdiri atas tiga tahap, yaitu: (1) analisis situasi didaktis sebelum pembelajaran yang wujudnya berupa Desain Didaktis
Hipotesis termasuk ADP; (2) analisis metapedadidaktik; dan (3) analisis retrosfektif yakni analisis yang mengaitkan hasil analisis situasi didaktis hipotesis dengan hasil analisis metapedadidaktik.

\section{Data, Instrumen dan Teknik Pengumpulan data}

Data, instrumen dan teknik penelitian dalam penelitian ini disajikan dalam table 2 .

Tabel 2. Teknik Pengumpulan Data dan Instrumen Penelitian

\begin{tabular}{lllll}
\hline No & Jenis data & \multicolumn{2}{l}{$\begin{array}{l}\text { Teknik } \\
\text { Pengumpulan }\end{array}$} & Instrumen \\
\hline 1 & $\begin{array}{l}\text { Kemampuan } \\
\text { kritis }\end{array}$ & berpikir & Tes & $\begin{array}{l}\text { Soal kemampuan } \\
\text { berpikir kritis }\end{array}$ \\
\hline 2 & Penilaian Bahan Ajar & $\begin{array}{l}\text { Non tes berupa } \\
\text { angket }\end{array}$ & $\begin{array}{l}\text { Angket validasi bahan } \\
\text { ajar }\end{array}$ \\
\hline 3 & Praktikalitas & $\begin{array}{l}\text { Non tes berupa } \\
\text { angket }\end{array}$ & Angket praktikalitas \\
\hline
\end{tabular}

Teknik Pengolahan Data

Sedangkan untuk teknik pengolahan data yang digunakan dalam penelitian ini adalah sebagai berikut.

1. Analisis learning obstacle

2. Analisis validasi bahan ajar, dengan teknik perhitungan sebagai berikut:

$V_{i}=\frac{T S_{e}}{T S_{h}} \times 100 \% \quad i=1,2,3,4$

Setelah masing-masing uji validasi hasilnya diketahui, peneliti dapat melakukan perhitungan validitas gabungan ke dalam rumus berikut:

Keterangan:

$$
V=\frac{V_{1}+V_{2}+V_{3}+V_{4}}{4}=\cdots .
$$

$\mathrm{V}=$ validasi gabungan

$V_{i}=$ validasi dari validator ke-i

$T S_{e}=$ total skor empirik yang dicapai berdasarkan penilaian validator

$T S_{h}=$ total skor yang diharapkan

Kriterianya sebagai berikut:

Tabel 3. Kriteria Validitas Bahan Ajar

\begin{tabular}{cl}
\hline Interval Validitas & \multicolumn{1}{c}{ Tingkat Validitas } \\
\hline $80 \%<V \leq 100 \%$ & Sangat valid atau dapat digunakan tanpa revisi \\
$60 \%<V \leq 80 \%$ & $\begin{array}{l}\text { Cukup valid atau dapat digunakan namun perlu } \\
\text { direvisi kecil }\end{array}$ \\
& Kurang valid, disarankan tidak dipergunakan \\
& karena perlu revisi besar \\
& Tidak valid, tidak boleh digunakan \\
& Sangat tidak valid atau tidak dapat digunakan \\
\hline
\end{tabular}

Sumber: Akbar (2013) 
3. Analisis Uji Praktikalitas, pemberian nilai praktikalitas dengan menggunakan rumus:

$$
P=\frac{\sum F}{N} \times 100 \%
$$

Dengan keterangan:

$\mathrm{P}=$ nilai akhir

$$
\begin{aligned}
& \mathrm{F}=\text { perolehan skor } \\
& \mathrm{N}=\text { skor maksimum }
\end{aligned}
$$

Setelah perhitungan data dapat diinterpretasikan dengan menggunakan kriteria berikut.

Tabel 4. Kategori Praktikalitas Perangkat Penilaian

\begin{tabular}{cc}
\hline Nilai $(\%)$ & Kategori \\
\hline $80<P \leq 100$ & Sangat Praktis \\
\hline $60<P \leq 80$ & Praktis \\
\hline $40<P \leq 60$ & Cukup Praktis \\
\hline $20<P \leq 40$ & Kurang Praktis \\
\hline$P \leq 20$ & Tidak Praktis \\
\hline
\end{tabular}

\section{HASIL PENELITIAN DAN PEMBAHASAN}

Dari ketiga tahap DDR dihasilkan modul yang valid dan praktis. Berikut dijelaskan berdasarkan tiap tahap dari DDR:

\section{Analisis data dan deskripsi tahap situasi didaktis}

Tahap situasi didaktis diawali dengan mencari learning obstacle. Suryadi (2013) mengemukakan bahwa salah satu aspek yang perlu menjadi pertimbangan guru dalam mengembangkan antisipasi didaktis pedagogis adalah adanya learning obstacle khususnya yang bersifat epistimologis. Pendapat lain dikemukakan oleh Wahyuni (2017) langkah pertama perlu diadakan penelitian yang mengidentifikasi dan menganalisis kemampuan matematis apa saja yang dipandang masih kurang dimiliki siswa dalam proses pembelajaran. Learning obstacle
Sumber: Riduwan (Hamdunah: 2015) epistimologis yang ditemui oleh siswa. Dalam penelitian ini secara umum ditemukan hambatan belajar: (a) siswa kesulitan dalam menjelaskan secara sederhana maupun kompleks, (b) siswa kesulitan menerjemahkan soal cerita ke dalam bentuk matriks, (c) siswa kesulitan menarik kesimpulan, dan (d) terjadinya kekeliruan perhitungan yang dialami siswa. Berdasarkan learning obstacle yang sudah dicari maka disusunlah situasi didaktis dan pedagogis untuk mengatasi learning obstacle tersebut. Wahyuni (2017) mengemukakan bahwa tahap kedua setelah diidentifikasi kesulitan yang ditemui, barulah ditawarkan pemecahannya berupa pengembangan bahan ajar, penerapan model, pendekatan, atau metode pembelajaran matematika tertentu. Maka berdasarkan pendapat tersebut peneliti membuat pemecahannya berupa pengembangan bahan ajar berupa modul. Langkah selanjutnya yang dilakukan adalah 
membuat situasi didaktis berdasarkan LO, sebagaimana pendapat yang diekemukakan oleh Roeroe (2011) pada saat merancang sebuah situasi didaktis, sekaligus juga perlu memikirkan prediksi respons siswa atas situasi tersebut serta antisipasinya sehingga tercipta situasi didaktis baru. Oleh karena itu setelah mencari learning obstacle, peneliti membuat situasi didaktis yang berisi antisipasi didaktis dan respons siswa berdasarkan learning obstacle yang telah dicari. Menurut Akbar (2013) desain didaktis yang telah dibuat harus divalidasi oleh ahli, hal ini dilakukan untuk menghasilkan desain didaktis yang memiliki kriteria kevalidan. Adapun berdasarkan perhitungan kumulatif perolehan skor tiap validator diperoleh: validator 1 memberikan persentase skor $83,82 \%$ dengan interpretasi sangat valid, validator 2 memberikan persentase skor $95,58 \%$ dengan interpretasi sangat valid dan validator 3 memberikan persentase skor $92,64 \%$ dengan interpretasi sangat valid. Kemudian dari ketiga vakidator tersebut dihitung persentase kumulatifnya sebesar 90,68\%. Berdasarkan perolehan skor tersebut maka bahan ajar diinterpretasikan sangat valid dan dapat diimplementasikan. Adapun validator memberikan saran agar modul disempurnakan.

\section{Analisis data dan deskripsi tahap metapedidaktik}

Pada tahap metapedadidaktik adalah kegiatan mengamati prediksi repons yang telah dibuat sesuai atau tidak. Kegiatan mengamati respons pada tahap metapedadidaktik memperoleh hasil yang menjelaskan bahwa sebagian besar prediksi respons yang sudah disusun sesuai dengan respons siswa pada saat implementasi. Namun ada beberapa hal terjadi di luar prediksi, seperti siswa kesulitan menerjemahkan soal cerita ke dalam bentuk matriks. Walaupun dalam modul sudah disediakan contoh soal terbimbing mengenai menerjemahkan soal cerita ke dalam matriks tetapi hubungan pedagogis antara guru dengan siswa lebih dibutuhkan oleh siswa.

\section{Analisis data dan deskripsi tahap restrofektif}

Menurut Roeroe (2011) dari ketiga tahapan dalam DDR akan diperoleh desain didaktis empirik yang tidak tertutup kemungkinan untuk terus disempurnakan melalui tiga tahapan DDR. Hal yang dikemukakan diatas dijadikan landasan oleh peneliti untuk menganalisis learning obstacle kembali guna melihat apakah desain bahan ajar yang dihasilkan perlu disempurnakan kembali atau tidak. Dalam penelitian ini sebagian besar learning obstacle tidak muncul kembali. Namun ada beberapa learning obstacle yang masih ada, seperti menerjemahkan soal cerita ke dalam bentuk matriks, penggunaan kaidah matriks pada penyelesaian masalah soal cerita, dan kemampuan menjelaskan siswa. Sedangkan untuk praktikalitas kegunaan bahan ajar yang diisi oleh siswa setelah implementasi bahan ajar diperoleh hasil perhitungan sebagai berikut, indikator 1 yaitu 
kemudahan pengguna memperoleh persentase sebesar $75,6 \%$ dengan interpretasi praktis, indikator 2 yaitu efisiensi waktu memperoleh persentase sebesar $64 \%$ dengan interpretasi praktis, indikator 3 yaitu manfaat memperoleh persentase sebesar $74,9 \%$ dengan interpretasi praktis. Adapun perhitungan yang dihitung secara keseluruhan diperoleh persentase sebesar 73\% dengan interpretasi praktis. Berdasarkan perhitungan tersebut maka dapat disimpulkan bahwa bahan ajar matriks berbasis kemampuan berpikir kritis praktis digunakan oleh siswa dalam pembelajaran matematika.

\section{SIMPULAN DAN SARAN}

\section{Simpulan}

Berdasarkan hasil deskripsi dan analisis data yang telah diperoleh pada penelitian Didactical Design Research (DDR) diperoleh kesimpulan sebagai berikut.

Bahan ajar berupa modul berbasis kemampuan berpikir kritis siswa pada materi matriks ini dibuat berdasarkan hasil dari analisis yang ada pada tahapan model pengembangan Didactical Design Research (DDR). Pada tahap analisis situasi didaktis dilakukan analisis learning obstacle dengan menghasilkan sembilan learning obstacle. Kemudian dibuat tabel antisipasi didaktis sebagai landasan pembuatan modul sesuai dengan learning obstacle. Tahap analisis situasi didaktis menghasilkan modul dengan kriteria sangat valid dan dapat diimplementasikan. Kemudian tahap kedua adalah analisis metapedadidaktik dihasilkan sebagian besar prediksi respons siswa sesuai, ada tiga respons siswa yang terjadi di luar prediksi. DDR diakhiri dengan tahap restrofektif, pada penelitian ini dilakukan analisis learning obstacle kembali. Setelah diimplementasikan bahan ajar memiliki akibat yaitu dapat mengatasi learning obstacle yang sudah dianalisis sebelumnya, tetapi masih ada learning obstacle yang muncul sehingga modul perlu disempurnakan. Bahan ajar berupa modul berbasis kemampuan berpikir kritis siswa pada materi matriks ini dinilai praktis karena pada aspek angket praktikalitas dengan indikator kemudahan penggunaan, efisiensi waktu dan manfaat dinilai praktis oleh pengguna.

\section{Saran}

Berdasarkan kesimpulan hasil penelitian di atas, maka saran yang dapat peneliti berikan adalah dalam penelitian ini learning obstacle tidak tuntas teratasi semua. Diantaranya adalah menentukan strategi dan teknik dapat diatasi dengan lebih banyak memunculkan soal cerita kontekstual. Serta untuk penelitian selanjutnya diharapkan dapat mengembangkan kembali antisipasi didaktis pedagogis agar tidak ditemukannya learning obstacle kembali.

\section{DAFTAR PUSTAKA}

Akbar, S. (2013). Instrument Perangkat Pembelajaran. Bandung: PT remaja Rosdakarya Offset.

Delima, N., Fitrizia, R. (2017). Pengembangan Model Comprehensive 
MathematicsInstruction

(CMI)

dalam Membangun Kemampuan Mathematical Thinking Siswa. JNPM (Jurnal Pendidikan Matematika).Vol 1, No. 1, Hal. 118.

Hamdunah. (2015). Praktikalitas

Pengembangan

Modul

Kontruktivisme Dan Website

Pada Materi Lingkaran Dan Bola.

Lemma Volume II, No.1.

Sumatera Barat.

Roeroe, M. B. (2011). Didactical Design research (DDR) Dalam Pengembangan Pembelajaran Kependidikan. Ed Vokasi, Volume 2, No. 2, ISSN. 2087- 3581. Manado.

Suryadi, D. (2013). Didactical Design Research (DDR) dalam Pengembangan Pembelajaran Matematika. Bandung.

Wahyuni, I. (2017). Desain Bahan Ajar Berbasis Aktivitas Penalaran Matematis Pokok Bahasan Bilangan Kompleks, Fungsi Kompleks dan Transformasi Elementer. Jurnal Euclid, Vol. 5, No. 1, pp. 45. Cirebon.

Wahyuni, R. Efuansyah. (2018). Model Pembelajaran Missouri Mathematics Project (MMP) Menggunakan Strategi Think Talk
Write (TTW) Terhadap

Kemampuan Berpikir Kritis Dan Kemampuan Pemecahan Masalah. JNPM Volume 2, No.1, Hal.24. Sumatera Selatan.

Kodir, A. (2010). Strategi Belajar Mengajar. Bandung: Pustaka Setia.

Prastowo, A. (2011). Panduan Kreatif Membuat Bahan Ajar Inovatif: Menciptakan Metode Pembelajaran Menarik dan Menyenangkan. Yogyakarta: Diva press.

Hendrickson, S., Hilton, S. C., \& Bahr, D. (2008). The Comprehensive Mathematics Instruction (CMI) Framework: A new lens for examining teaching and learning in the mathematics clasroom.

Miliyawati, B. (2017). Reformulasi Strategi Habits of Mind Matematis Terhadap Kemampuan Mathematical Critical Thinking Dalam Mewujudkan Generasi Emas Berkarakter. JNPM Vol. 1, No.1, Hal. 24. Bandung.

Mardiana, H. (2013). Pengembangan Desain Pembelajaran IPA Berbasis Kontruktivisme tentang gaya magnet di sekolah dasar. Bandung: UPI. 